\title{
Cutaneous reactions caused by nitrofurazone
}

\author{
Serap Gunes Bilgilii ${ }^{1}$, Goknur Ozaydin-Yavuz ${ }^{1}$, Ibrahim Halil Yavuz ${ }^{1}$, Mehmet Ali Bilgili², Ayse Serap Karadag ${ }^{3}$
}

${ }^{1}$ Department of Dermatology, Faculty of Medicine, Van Yuzuncu Yil University, Van, Turkey 2Department of Emergency Medicine, Van Training and Research Hospital, Health Sciences University, Van, Turkey ${ }^{3}$ Department of Dermatology, School of Medicine, Istanbul Medeniyet University, Istanbul, Turkey

Adv Dermatol Allergol 2019; XXXVI (4): 398-402 DOI: https://doi.org/10.5114/ada.2019.87444

\begin{abstract}
Introduction: Allergic contact dermatitis (ACD) is a form of dermatitis due to type 4 hypersensitivity reaction that occurs when the skin comes into contacts with the topical product. Topical nitrofurazone is a widely used antimicrobial drug in our country which is well known to cause ACD.

Aim: In this study, ACD cases with different clinical features attributed to the use of nitrofurazone were evaluated. Material and methods: Patients hospitalized in our clinic between 2013 and 2017 with ACD diagnosis due to nitrofurazone were evaluated. The patient age, gender, atopy histories, clinical features, dissemination of the lesions, treatment given were reviewed.

Results: In a 5-year period, 58 cases were identified and their data were analysed. Twelve patients were female (21\%), 46 patients were male (79\%). Clinical presentations were dyshidrosiform (45\%), excoriated papules and plaques (33\%), combined (21\%), and erythroderma in one patient. The dissemination was generalized in 34 patients, localized in 14 patients, and local spread in 10 patients. The mean hospitalization time was $7 \pm 3$ days, and ranged from 3 to 18 days.

Conclusions: There may be widespread and severe ACD due to the use of nitrofurazone. Topical nitrofurazone should not be applied on damaged skin as sensitization may develop. Patients and physicians should be aware of the ACD risk associated with topical nitrofurazone, which is also commonly used as self-medication, physicians should take a detailed history of the drug use and products containing nitrofurazone should not be used in conditions where skin integrity is not intact, whenever possible.
\end{abstract}

Key words: allergic contact dermatitis, nitrofurazone.

\section{Introduction}

Allergic contact dermatitis (ACD) is an inflammatory condition due to type 4 delayed hypersensitivity reaction [1]. After topical products come into contact with the skin, itchy, erythematous and oedematous papules, plaques and vesicles are seen in the area of contact. Although the reaction is limited to the site of exposure in the early period, it may spread to additional areas with time or repeated exposure (autoeczematisation) $[2,3]$. The clinical presentation varies according to the potency and contact time of the allergen, the reaction zone and the degree of sensitization of the individual $[4,5]$.

Nitrofurazone is frequently used in our country, especially in surgical clinics, and the resulting ACD cases are directed to dermatology clinics.

\section{Aim}

In this study, ACD cases with different clinical features attributed to the use of nitrofurazone were evaluated retrospectively.

\section{Material and methods}

Patients hospitalized with diagnosis of nitrofurazoneassociated ACD at the 5-year period in our dermatology clinic (between January 2013 and December 2017) were evaluated retrospectively and cross-sectionally. Medical records of patients with nitrofurazone-associated ACD were collected and analysed. Patients without definite diagnosis and using another topical or systemic drug were not included in the study. The medical records were reviewed for age, gender, indications for nitrofurazone

Address for correspondence: Assoc. Prof. Serap Gunes Bilgili, Department of Dermatology, Faculty of Medicine, Van Yuzuncu Yil University, Van, Turkey, e-mail: drserapgunes@yahoo.com Received: 27.03.2018, accepted: 9.04.2018. 

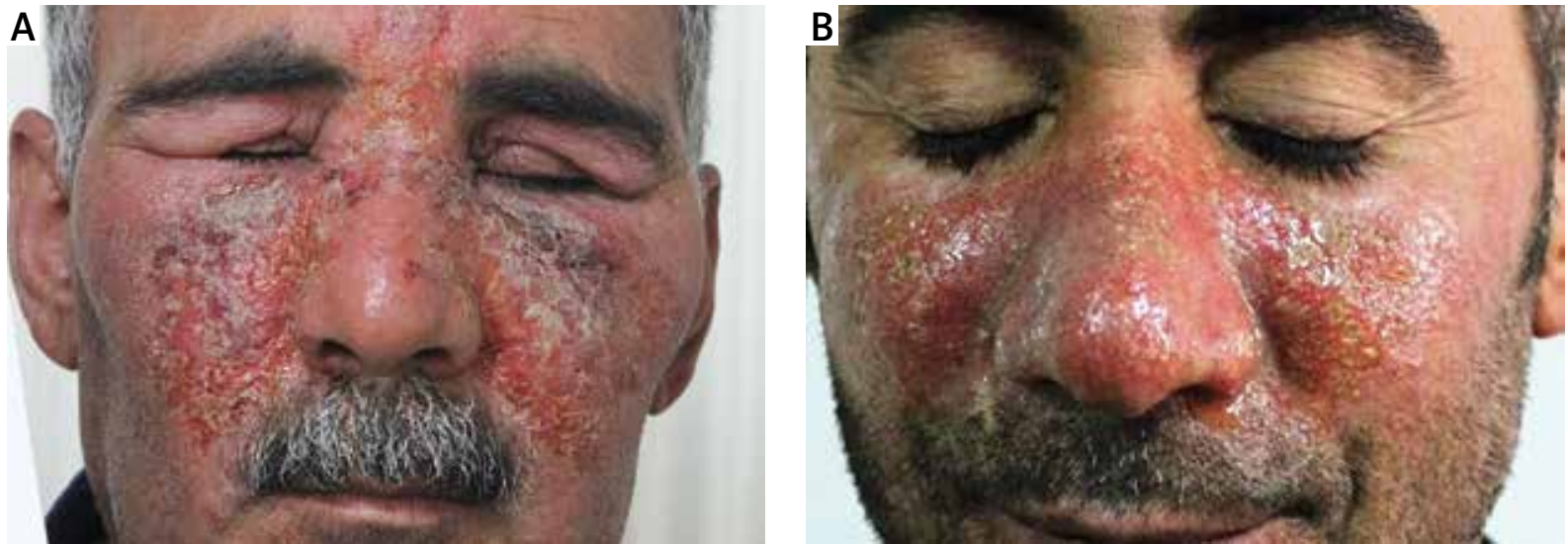

Figure 1 A, B. Nitrofurazone-induced allergic contact dermatitis on the face

use, localization and dissemination of lesions, clinical presentation type, atopy history, presence of eosinophilia, hospitalization time, treatment given and initial dose of the treatment.

The diagnosis of ACD was made based on clinical features and history. Diagnosis in some of the patients was supported by histopathology. If the ACD is limited to the area of the topical application only, it is considered to be localized, if it is spreading to areas remote from the application area it is considered to be generalized and if more than $80 \%$ of the body are covered with erythema and squama, it is considered to be erythroderma.

At least 1 month after the completion of the treatments, a patch test was performed with the topical nitrofurazone soluble dressing cream used by the patients who accepted the application. The topical nitrofurazone soluble dressing cream was applied in Patch Test Chambers (Van der Bend, Brielle, Netherlands) to the upper back for $48 \mathrm{~h}$. Test areas were evaluated at days (D) 2, 3 and 4 . According to the criteria established by the International European Contact Dermatitis Research Group (ICDRG), the test was not performed in the presence of active dermatitis, if topical corticosteroids were used in the last week, if systemic corticosteroids were used in the last 4 weeks, in immunosuppressive drug use and during pregnancy.

\section{Statistical analysis}

The obtained data were analysed using the SPSS (Statistical Packages for Social Analysis) version 15.0 program. The results were analysed descriptively by percentage and on average.

\section{Results}

Fifty-eight patients who were followed-up and treated by hospitalization at our clinic in a 5-year period (2013-2017) were included in the study. Forty-six patients were male (79\%), and 12 patients were female (21\%). The mean age was $51 \pm 17$ years (minimum age: 14 years, maximum age: 85 years).

The reasons for the use of nitrofurazone cream were skin wounds in 33 (57\%) patients, postoperative surgical procedures in 9 (15\%) patients, infected eczema in $6(10 \%)$ patients, burns in $5(9 \%)$ patients, stasis dermati-

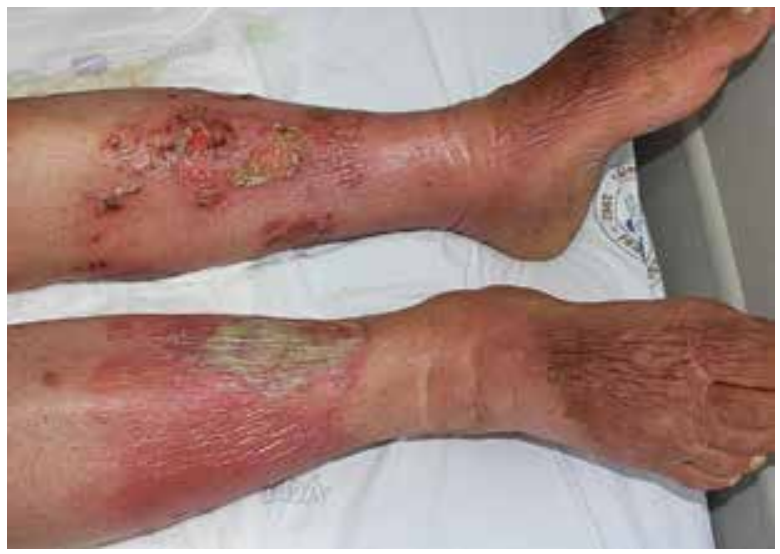

Figure 2. Nitrofurazone-induced allergic contact dermatitis on the lower extremities

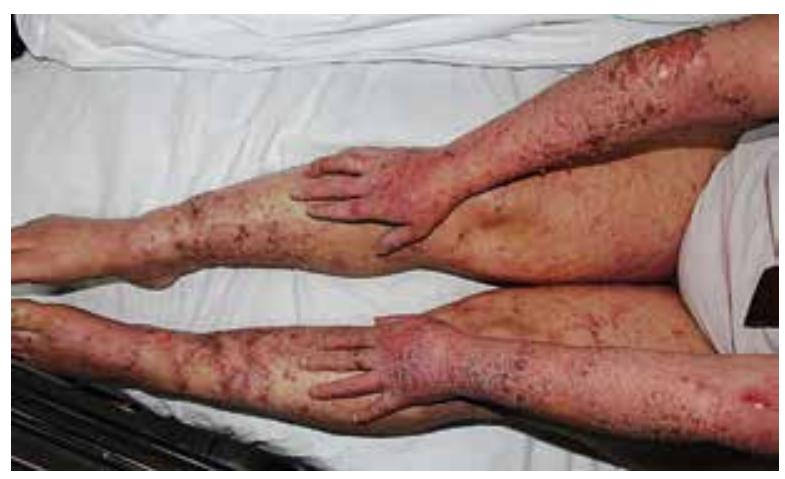

Figure 3. Nitrofurazone-induced allergic contact dermatitis on the upper and lower extremities 

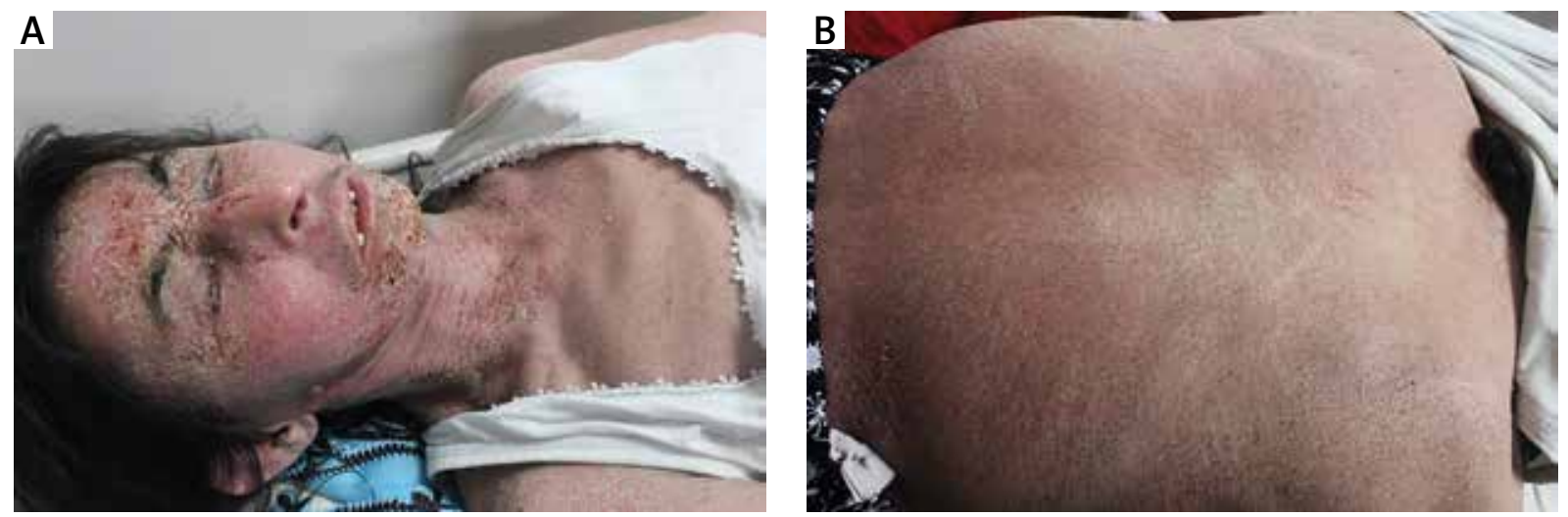

Figure 4 A, B. Allergic contact dermatitis in erythroderma morphology after the use of nitrofurazone for facial burn

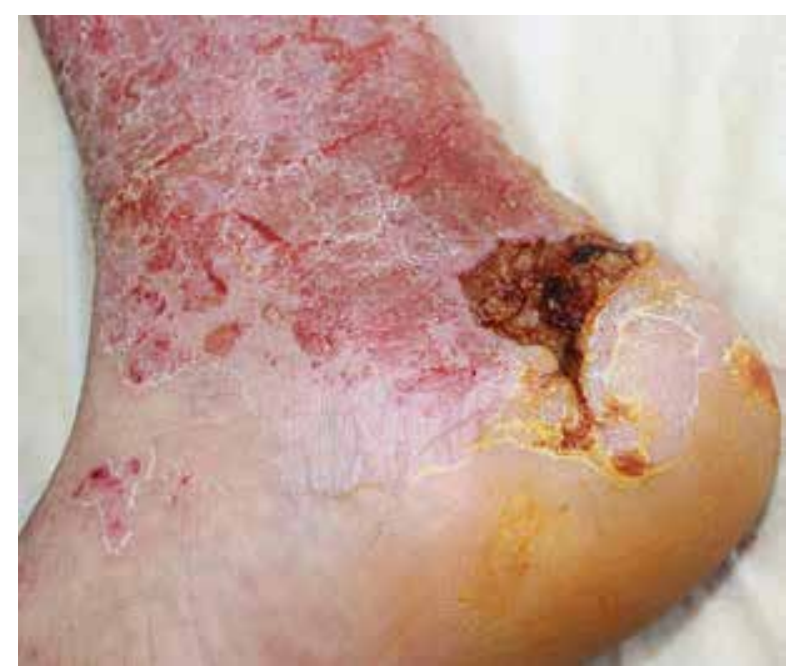

Figure 5. Allergic contact dermatitis after the administration of nitrofurazone for the ulcer of the ankle

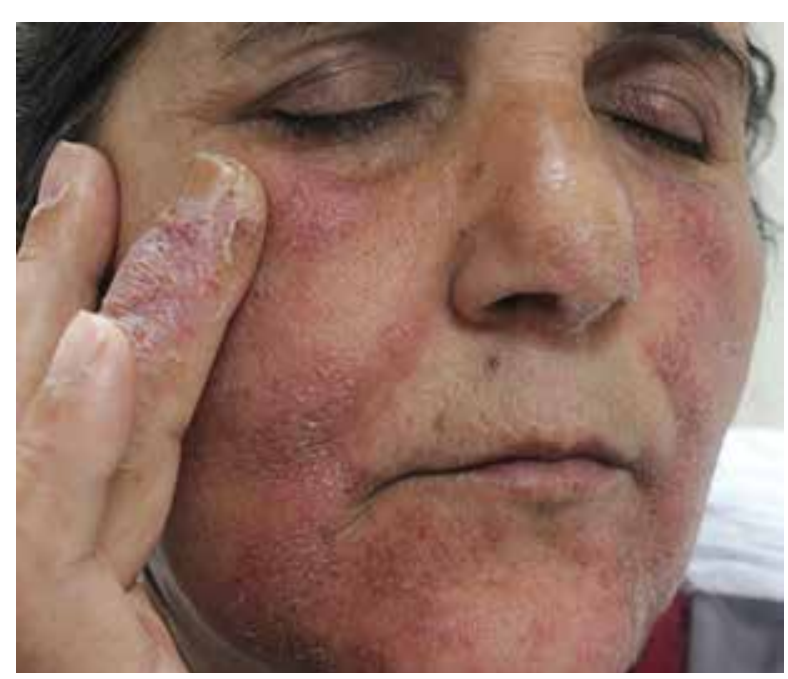

Figure 6. Nitrofurazone-induced allergic contact dermatitis with the erythemato-squamous pattern after application to a wound in the finger tis/stasis ulcer in 4 (7\%) patients and amputation stump in $1(2 \%)$ patient. Nitrofurazone cream was applied to the hand in 7 (12\%) patients, to the upper limb in 11 (19\%) patients, to the ankle in 12 (20\%) patients, to the lower limb in 18 (31\%) patients, to the face in 7 (12\%) patients (Figures $1 \mathrm{~A}, \mathrm{~B})$, to the body in 1 (2\%) patient, to the axilla in $1(2 \%)$ patient and to the genital area in $1(2 \%)$ patient.

Clinical presentations were dyshidrosiform in 26 (45\%) patients (Figure 2), excoriated papules and plaques in 19 (33\%) patients (Figure 3), combined in 12 (21\%) patients, and erythroderma in 1 patient (Figures 4 A, B). The dissemination was generalized in 34 (59\%) patients, localized in 14 (24\%) patients and local spread in 10 patients $(17 \%)$ (Figures 5, 6). The clinical characteristics of the patients are shown in a table (Table 1 ).

Eosinophilia was present in $50 \%$ of the patients (29 patients). The atopy history was present in 4 (7\%) patients. Patch testing was performed in 15 patients and patch test results were negative in all patients on D2, D3 and D4.

The mean hospitalization time was $7 \pm 3$ days, and ranged from 3 to 18 days. During treatment, topical corticosteroids were sufficient in $3(5 \%)$ patients but systemic prednisolone was required for less than 5 days in $33(57 \%)$ patients and systemic prednisolone was needed for more than 5 days in 22 (38\%) patients. The initial dose of systemic prednisolone was 40-60 mg/day. All patients recovered and no complications related to treatment were developed.

\section{Discussion}

Nitrofurazone is a topical antimicrobial agent with broad-spectrum antibacterial activity. In addition to antibiotic creams, it is still used in veterinary medicine and as an animal feed additive, and has occupational contact dermatitis potential. It contains $0.2 \%$ nitrofurazone and polyethylene glycol (PEG) 300, PEG 1000 and PEG 4000 as vehicle $[6,7]$. It is highly preferred by plastic surgeons, general surgeons and family physicians in our country 
and is used for chronic leg ulcers, superficial skin infections, ulcers, burns and other forms of chronic dermatitis. The nitrofurazone dressing soluble cream form used in our study included $0.2 \%$ nitrofurazone and PEG 300, PEG 1000 and PEG 4000.

Nitrofurazone sensitization has been known for many years. Studies reported in the literature generally show nitrofurazone susceptibility rates in patch test results with topical drugs in ACD suspected cases [8, 9]. There are not many studies reporting only nitrofurazone-related ACDs. Nitrofurazone-related ACDs have been reported as case reports and no large series has been reported [10, 11].

In 1948, Downing and Becker reported a prevalence of nitrofurazone sensitivity of $6 \%$ in 233 patients with various dermatitis types [12]. Bajaj and Gupta reported that nitrofurazone was the most sensitizing agent in 390 patients and that $36.2 \%$ of the patients had a positive reaction due to nitrofurazone [8]. In a retrospective study conducted by Ozkaya and Kılıç, 836 patients with suspected ACD were evaluated during a 20-year period between 1996 and 2015. ACD that was confirmed by the patch test against nitrofurazone developed in 28 of these patients. The most common dissemination pattern was generalized dissemination, followed by localized dissemination [9]. Our study covers a period of 5 years and contains 58 cases of ACD caused by nitrofurazone. In our study, contact dermatitis lesions due to nitrofurazone were generalized in $59 \%$ of patients, localized in $24 \%$ and local spread in $17 \%$. Clinical presentations were dyshidrosiform in $45 \%$ of patients, excoriated papules and plaques in $33 \%$ of patients, combined in $21 \%$ of patients, and erythroderma in $1 \%$ of patients.

In studies conducted by Ozkaya and Polat Ekinci on 53 cases with foot contact dermatitis, nitrofurazone $(n=8)$ was the most common cause of foot allergic contact dermatitis. Clinically, they reported that nitrofurazone cream is the most common cause of ACD showing unilateral involvement and dyshidrosiform morphology [13]. In our study, dyshidrosiform was found in $45 \%$ of patients.

Positive reactions may not always be achieved despite the use of allergens at appropriate concentrations in patch testing, which is extremely important in the assessment of ACD [14]. Ozkaya and Kılıç reported that late positive reactions to nitrofurazone, in which the reactions started on D4 or later (D7) in more than one-third of patients [9]. Because our study did not have late reading (D7), patch test results may be negative. Test reactions are usually read at D2 and D3, but where possible, D4 and D7 can also be evaluated.

Due to the high incidence of allergic reactions, the use of nitrofurazone in Western countries has been largely abandoned [7]. Nitrofurazone or PEG allergy has not been reported in recent studies investigating contact sensitivity to vehicle components in patients with chronic leg ulcer or stasis dermatitis in the United States
Table 1. Characteristics of 58 patients with allergic contact dermatitis due to nitrofurazone

\begin{tabular}{lc}
\hline Parameter & $\begin{array}{c}\text { Number of patients }(N=58) \\
n(\%)\end{array}$ \\
\hline Gender, female/male & $12 / 46$ \\
\hline $\begin{array}{l}\text { Age, median } \\
\text { (minimum-maximum) }\end{array}$ & $51 \pm 17(14-85$ years $)$ \\
\hline
\end{tabular}

Reason for use of the topical

nitrofurazone:

\begin{tabular}{lc}
\hline Skin wounds & $33(57)$ \\
\hline $\begin{array}{l}\text { Postoperative surgical } \\
\text { procedures }\end{array}$ & $9(15)$ \\
\hline Infected eczema & $6(10)$ \\
\hline Burns & $5(9)$ \\
\hline Stasis dermatitis & $4(7)$ \\
\hline Amputation stumps & $1(2)$
\end{tabular}

Initial localization:

\begin{tabular}{lc}
\hline Hand & $7(12)$ \\
\hline Upper extremities & $11(19)$ \\
\hline Ankle & $12(20)$ \\
\hline Lower extremities & $18(31)$ \\
\hline Face & $7(12)$ \\
\hline Axilla & $1(2)$ \\
\hline Genital & $1(2)$ \\
\hline Trunk & $1(2)$
\end{tabular}

Morphologic pattern:

\begin{tabular}{lc}
\hline Dyshidrosiform & $26(45)$ \\
\hline Erythemato-squamous & $19(33)$ \\
\hline Combined & $12(21)$ \\
\hline Erythroderma & $1(2)$ \\
\hline
\end{tabular}

Treatment:

\begin{tabular}{lc}
\hline Topical corticosteroids & $3(5)$ \\
\hline $\begin{array}{l}\text { Systemic prednisolone (short- } \\
\text { term treatment for } 5 \text { days) }\end{array}$ & $33(57)$ \\
\hline $\begin{array}{l}\text { Systemic prednisolone (long- } \\
\text { term treatment for } 5 \text { days) }\end{array}$ & $22(32)$ \\
\hline
\end{tabular}

or Europe [15-17]. Therefore, PEG 400 was removed from the North American Contact Dermatitis Group (NACDG) patch test series [15]. However, nitrofurazone is found in $1 \%$ petrolatum in India patch test series $[18,19]$. Recent studies reported in India have shown that nitrofurazone sensitivity is beginning to decrease $[19,20]$. The use of nitrofurazone in our country is very common. Thus, we think that it would be more beneficial to make additions 
to the patch test considering the conditions of the countries and the active agents in commonly used drugs.

In a study conducted by Yılmaz et al., contact allergic findings (erythema, bullae, pruritus) related to nitrofurazone were found in 4 (2\%) of 200 patients who had various injuries (diabetic foot, pressure sore, burn, venous ulcer, traumatic skin wounds, skin infections, laceration, infected incision) and treated with topical nitrofurazone cream in the plastic surgery department. Thus, they have suggested that topical nitrofurazone is a good choice for infecting and open wounds [21]. There is no detailed information on the duration of nitrofurazone use in the study conducted by Yılmaz et al. The sensitization phase depending on the topical medication is important in the development of ACD. Most reactions do not occur at first use, but occur at the second use after the sensitization phase has developed. The sensitization phase covers a period of 10-14 days. The reaction that occurs in reexposure is rapid and more intense [1]. We believe that the low nitrofurazone sensitivity in this study may be dependent on the duration. Our patients had repeated nitrofurazone use or prolonged use times of up to 2-3 weeks.

Nitrofurazone-associated ACD may be severe and may require hospitalization or systemic corticosteroid therapy in a significant proportion of patients [22]. Our study comprised patients who were hospitalized and therefore the reactions were very severe. Considering that most ACD patients are outpatients, we believe that the results will be more realistic in the series that will include inpatients.

\section{Conclusions}

Nitrofurazone cream is still a widely used drug in the wound treatment by physicians in Turkey. Limiting the use of this medicine by physicians will be beneficial for patients when considering the dermatological side effects that may be life threatening such as common erythroderma.

\section{Conflict of interest}

The authors declare no conflict of interest.

\section{References}

1. Tan CH, Rasool S, Johnston GA. Contact dermatitis: allergic and irritant. Clin Dermatol 2014; 32: 116-24.

2. Spring S, Pratt M, Chaplin A. Contact dermatitis to topical medicaments: a retrospective chart review from the Ottawa Hospital Patch Test Clinic. Dermatitis 2012; 23: 210-3.

3. Mark BJ, Slavin RG. Allergic contact dermatitis. Med Clin North Am 2006; 90: 169-85.

4. Kostner L, Anzengruber F, Guillod C, et al. Allergic contact dermatitis. Immunol Allergy Clin North Am 2017; 37: 141-52.

5. Onder M. Allergic contact dermatitis. Turkderm 2009; 43: 3-9.
6. Moreno Escobosa MC, Moya Quesada MC, Cruz Granados S, Amat López J. Contact dermatitis to antibiotic ointments. J Investig Allergol Clin Immunol 2009; 19: 510-1.

7. Gehrig KA, Warshaw EM. Allergic contact dermatitis to topical antibiotics: epidemiology, responsible allergens, and management. J Am Acad Dermatol 2008; 58: 1-21.

8. Bajaj AK, Gupta SC. Contact hypersensitivity to topical antibiotics. Int J Dermatol 1986; 25: 103-5.

9. Ozkaya E, Kılıc S. Polyethylene glycol as marker for nitrofurazone allergy: 20 years of experience from Turkey. Contact Dermatitis 2018; 78: 211-5.

10. Prieto A, Baeza ML, Herrero T, et al. Contact dermatitis to furacin. Contact Dermatitis 2006; 54: 126.

11. Guijarro SC, Sánchez-Pérez J, García-Díez A. Allergic contact dermatitis to polyethylene glycol and nitrofurazone. Am J Contact Dermat 1999; 10: 226-7.

12. Downing JG, Brecker FW. Further studies in the use of furacin in dermatology. N Engl J Med 1948; 239: 862-4.

13. Ozkaya E, Polat Ekinci A. Foot contact dermatitis: nitrofurazone as the main cause in a retrospective, cross-sectional study over a 16-year period from Turkey. Int I Dermatol 2016; 55: 1345-50.

14. Akita H, Akamatsu H, Matsunaga K. Allergic contact dermatitis due to phenylephrine hydrochloride, with an unusual patch test reaction. Contact Dermatitis 2003; 49: 232-5.

15. Saap L, Fahim S, Arsenault E, et al. Contact sensitivity in patients with leg ulcerations: a North American study. Arch Dermatol 2004; 140: 1241-6.

16. Corazza M, Virgili A, Ricci M, et al. Contact sensitization to emulsifying agents: an underrated issue? Dermatitis 2016; 27: 276-81.

17. Erfurt-Berge C, Geier J, Mahler V. The current spectrum of contact sensitization in patients with chronic leg ulcers or stasis dermatitis - new data from the Information Network of Departments of Dermatology (IVDK). Contact Dermatitis 2017; 77: 151-8.

18. Narendra G, Srinivas CR. Patch testing with Indian standard series. Indian J Dermatol Venereol Leprol 2002; 68: 281-2.

19. Sharma VK, Sethuraman G, Garg T, et al. Patch testing with the Indian standard series in New Delhi. Contact Dermatitis 2004; 51: 319-21.

20. Bajaj AK, Saraswat A, Mukhija G, et al. Patch testing experience with 1000 patients. Indian J Dermatol Venereol Leprol 2007; 73: 313-8.

21. Yilmaz S, Saydam M, Seven E. Is nitrofurazone a potent sensitizer in surgical patients? Plast Reconstr Surg 2004; 114: 823-4.

22. Hull PR, de Beer HA. Topical nitrofurazone, a potent sensitizer of the skin and mucosae. South Afr Med J 1977; 52: 189-90. 